\title{
Study of the porous asphalt performance with cellulosic fibres
}

\author{
Márcia Lopes Afonso ${ }^{\mathrm{a}, *}$, Marisa Dinis-Almeida ${ }^{\mathrm{b}}$, Cristina Sena Fael ${ }^{\mathrm{b}}$ \\ ${ }^{a}$ C-MADE, Centre of Materials and Building Technologies, University of Beira Interior, Calçada Fonte do Lameiro, Edifício II das Engenharia, 6200-358 Covilhã, Portugal \\ ${ }^{\mathrm{b}}$ Centre of Materials and Building Technologies, University of Beira Interior, Calçada Fonte do Lameiro, Edifício II das Engenharia, 6200-358 Covilhã, Portugal
}

\section{H I G H L I G H T S}

- Porous asphalt presents a fine pellicle of bitumen in the aggregates coating.

- Cellulosic fibres avoid the binder drainage.

- The cellulosic fibres addition in porous asphalt is an eco-friendly solution.

- Porous asphalt with cellulosic fibres show good results to permanent deformation.

\section{A R T I C L E I N F O}

\section{Article history:}

Received 20 September 2016

Received in revised form 15 December 2016

Accepted 30 December 2016

Available online 7 January 2017

\section{Keywords:}

Cellulosic fibres

Porous asphalt

Particle loss

Stiffness

Water sensitivity

Permeability

Wheel Tracking

\begin{abstract}
A B S T R A C T
The porous asphalt (PA) use in road pavements surface layers is one of the most common solutions worldwide to address the climate changes impact like heavy rain. The aim of this study is to evaluate the performance of these mixtures with the cellulosic fibres addition, known for their adherence capacity between the aggregates and the binder. These will help to prevent the binder loss by drainage, which is one of the main problems of porous asphalt, since the fine aggregates content is reduced. Comparing to the conventional porous asphalt the cellulosic fibres addition improved performance to permanent deformation.
\end{abstract}

(c) 2017 Elsevier Ltd. All rights reserved.

\section{Introduction}

The cities growth, relating to population and infrastructures, has been leading to a progressive soil waterproofing [1]. This, associated with extreme climate changes, increases the floods and droughts associated risks, since it reduces the most favourable area for water infiltration $[2,3]$. This occurrence affects the urbanization hydrologic factors by increasing the surface runoff, the water quality deterioration and concentration of pollutants, reducing groundwater recharge [4-9]. The porous asphalt use in surface layers of road pavement is one of the solutions used worldwide to decrease the caused effects.

The porous asphalt can be applied both in conventional pavements with impermeable base layer, and also in permeable pavements with a fully constituted structure by porous layers [10-13].

\footnotetext{
* Corresponding author.

E-mail addresses: marcia.afonso@ubi.pt (M.L. Afonso), marisa.dinis@ubi.pt (M. Dinis-Almeida),cfael@ubi.pt (C.S. Fael).
}

In addition to the effects associated to surface runoff improvement, the application of these mixtures allows the decrease of the urban heat island effect, reduce the tires noise, the surface runoff and, consequently, the spray effect and aquaplaning, leading to a safer driving [14-16]. Noise reduction is also improved by the increase of porous asphalt air voids content with the help of the aggregates optimized sieve line [17,18]. Their disadvantages are, on the one hand, the load capacity reduction, mainly in permeable pavements, and on the other hand, periodic maintenance due to clogging, concerns that still are an investigation object [19-24].

The porous asphalt first generations were produced with high binder percentages to allow a better connection between the aggregates, emerging however, its hardening problem due to the mastic low amount [17]. Thus, nowadays, there are used polymer modified bitumen with differentiating characteristics, such as elasticity, aging resistance and plastic deformations, good adhesiveness with the aggregates and the low thermal susceptibility [25-27]. 
The problems related to environmental issues have motivated the research about eco-friendly materials. This fact combined with the relatively high binder percentage and with the need to improve the mixtures durability has led to the additives incorporation like the fibres, not only in asphalt mixtures but also in stone matrix asphalt and asphalt concrete. A wide variety of fibre types has been used in asphalt mixtures, including cellulose, mineral, synthetic polymer, glass fibres, newsprint, carpet fibres and recycled tire fibres [28-36]. Cellulosic fibres are the most commonly used additives [37-42]. The current study uses cellulosic fibres to improve porous asphalt performance. These fibres present a set of important advantages, such as wide availability at relatively low cost, recycling ability, biodegradability, non-hazardous nature, zero carbon footprint, and interesting physical and mechanical properties (low density and well-balanced stiffness, toughness and strength) $[43,44]$. One of the main objectives of cellulosic fibres is to stop binder drainage preventing its loss during storage and transport [45].

Thus, this research objective is to evaluate the porous asphalt performance incorporated with cellulosic fibres compared to porous asphalt without cellulosic fibres, named conventional. The mix design was initially performed for the four mixtures studied and the percentage influence of the fibres to be used. Subsequently, the performance was evaluated through laboratory tests of indirect tensile stiffness modulus, water sensitivity, permeability and permanent deformation. With this solution it is intended to develop resilience and adaptation better practices to the increase of extreme climate changes and respond to the sustainability current demands, through the eco-friendly materials use.

\section{Materials and methods}

The study began with the used materials characterization in the porous asphalt production. Then, it was performed the mix design study through the Cantabro test. Finally, the performance tests described in methods were performed.

The surface layer solution proposed in this article consists of a double porous layer in order to improve surface runoff and reduce the clogging problem $[21,25]$. Thus, in practice, it is first applied layer with coarse aggregate, which increases the air voids content, then the layer with fine aggregate that offers greater comfort to the wearer, reduces noise and at the same time has drainage capacity [25]. These two mixtures were produced without cellulosic fibres (PA01 with fine aggregate and PA02 with coarse aggregate) and with cellulosic fibres (PA1 with fine aggregate and PA2 with coarse aggregate).

\subsection{Materials}

This paper presents the four porous asphalt mixtures study composed of granitic origin natural aggregates, fillers, polymer modified bitumen and cellulosic fibres as an additive.

\subsubsection{Additive}

The cellulosic fibres used are granules made of natural cellulose fibres with bitumen mixture, traded with the name of Viatop Premium by JRS, J. Rettenmaier \& Söhne. Viatop Premium is a pelletized blend of $90 \%$ by weight of ARBOCEL ZZ $8 / 1$ and $10 \%$ by $50 / 70$ bitumen weight. These fibres may be used as additives in bituminous mixtures, in order to improve their characteristics, increasing its durability and performance. The fibres bituminous coating guarantees a quick and complete dispersion in the mixture having a stabilizing effect due to a dense three-dimensional fibre network. Since the porous asphalt has a structure with few fines and, consequently, a smaller contact surface between the coarse
Table 1

Cellulosic fibres Viatop Premium characteristics.

\begin{tabular}{ll}
\hline Granulated characteristics & \\
\hline Aspect & Cylindrical granules \\
Fibres content & 87 to $93 \%$ \\
Granules average length & 2 to $8 \mathrm{~mm}$ \\
Granules average diameter & $5 \pm 1 \mathrm{~mm}$ \\
Bulk density & 440 to $520 \mathrm{~g} / \mathrm{l}$ \\
Particle size distribution, \# $<4,5 \mathrm{~mm}$ & max. $10 \%$ \\
Bitumen characteristics included in the granulated & \\
Penetration (EN 1426$)$ a $25^{\circ} \mathrm{C}$ & $50 / 70(0.1 \mathrm{~mm})$ \\
Softening point (EN 1427$)$ & $46 / 54{ }^{\circ} \mathrm{C}$ \\
Fibres characteristics & \\
Basic composition & $\mathrm{Technical} \mathrm{cellulose} \mathrm{fibre}$ \\
Cellulose content & $80 \pm 5 \%$ \\
pH value (5 g/100 ml) & $7.5 \pm 1.0$ \\
Fibre average length & $1100 \mu \mathrm{m}$ \\
Fibre average diameter & $45 \mu \mathrm{m}$ \\
Particle density & $480 \mathrm{~kg} / \mathrm{m}^{3}$ \\
\hline
\end{tabular}

aggregates, the use of cellulosic fibres aims to increase the amount of mixture bitumen without checking drainage. These allow, on the one hand, the bituminous binder retention and, on the other hand, help the aggregates coating, meaning the formation of a bituminous layer with constant thickness. Thus, cellulosic fibres avoid the mastic efficacy loss. The detailed characterization is presented in Table 1.

\subsubsection{Binder}

The binder used in the porous asphalt production was PMB 45/80 Polymer Modified Bitumen, traded with the name of Elaster BM-3b, by CEPSA Portuguesa Petróleos, SA, indicated for porous asphalt and stone mastic asphalt use. This modified bitumen was obtained by a chemical reaction between a hydrocarbon binder and an elastomeric polymer, according to EN 14023 standard. The range of temperatures recommended for the mixing is between 155 to $165^{\circ} \mathrm{C}$ and the compacting is between 150 to $160^{\circ} \mathrm{C}$.

The bitumen characterization was based on the penetration test (EN 1426), with measured penetration value of $53 \mathrm{dmm}$, the softening point test (EN 1427), with measured value of $63.2^{\circ} \mathrm{C}$, and elastic recovery (EN 13398) with a result higher than $70 \%$.

\subsubsection{Particle size distribution determination}

This investigation was developed with natural aggregates of granitic origin due to these materials abundance in the central region of Portugal. The used granites were of different fractions (stone dust, 5/10 gravel and 5/15 gravel). In addition, all mixtures

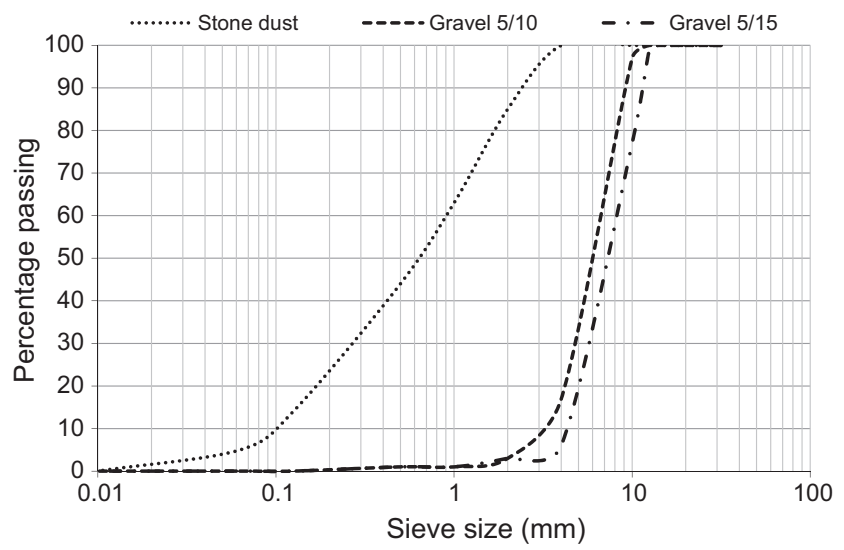

Fig. 1. Aggregates grading curves. 
Table 2

Requirements for porous asphalt.

\begin{tabular}{|c|c|c|c|c|c|}
\hline Properties & Portuguese Road Administration & SN 640 standard & Spanish Road Administration & UNHSC, 2014 & FHWA, 2015 \\
\hline Air voids content (\%) & $V \min 22-V \max 30$ & $\geqslant 20$ & $>20$ & $16-22$ & $>16$ \\
\hline$\%$ Bitumen, min & Bmin4.0 & $\geqslant 5$ & 4.3 & - & - \\
\hline Wet Cantabro test, $\max (\%)$ & $\leqslant 25$ & - & $\begin{array}{l}\leqslant 35(\text { T00 a T1 }) \\
\leqslant 40(\text { T2 а T3 })\end{array}$ & $\leqslant 20$ & - \\
\hline
\end{tabular}

incorporated hydraulic lime. However, new solutions have emerged as an alternative to fillers used in porous asphalt, such as waste bleaching clay, leading to good results [46].

The aggregates particle size analysis was performed according to the sieving method, EN 933-1 standard. In order to obtain a particle size with bigger nominal size of aggregates (coarse) and other with smaller nominal size (fine) due to double porous layer, two different grading envelopes were adopted. The PA 12.5 grading envelope was used for the mixture with coarse aggregates, according to the Portuguese Road Administration specifications [47]. Since these specifications do not include any other envelope for porous asphalt, PA 8 grading envelope was adopted for the mixture with fine aggregates, defined in Switzerland SN 640 431-7NA and 430a standards. Regarding the grading envelopes adopted, Fig. 1 shows the grading curves of each aggregate, with the exception of hydraulic lime which passes $100 \%$ in all sieves.

\subsection{Methods}

The experimental program began with the two porous asphalt mixtures study (coarse and fine) using the PBM 45/80 modified bitumen. These were formulated as surface layers, meeting the requirements of Table 2 according to the Portuguese Road Administration [47], the Spanish Road Administration [48] and Switzerland SN 640 standard. Studies by University of New Hampshire Stormwater Center (UNHSC) [49] and the Federal Highway Administration [21] were also considered, indicating different air voids content from the established in Portugal for these mixtures. Thus, these foreign references were considered due to recently demonstrated experience.

After selecting the optimum bitumen percentage of mixtures, the influence of the addition of cellulosic fibres was analysed. Through the binder drainage test was selected cellulosic fibres percentage that had the lowest drainage. Later, two porous asphalt mixtures were done with the cellulosic fibres adopted percentage. The four studied mixtures performance was evaluated by the stiffness, water sensitivity, permeability and permanent deformation.

\subsubsection{Optimum bitumen percentage for the mixtures without cellulosic fibres}

The porous asphalt mix design, PA01 (porous asphalt with fine aggregates, without fibres) and PA02 (porous asphalt with coarse aggregates, without fibres), was obtained by meeting the grading envelopes and the determination of the initial bitumen percentage (with $\pm 0.5 \%$ ) through the aggregates specific surface area. The selection of optimum bitumen percentage was obtained by meeting the stablished requirements in Table 1 . For this purpose, there were produced eight cylindrical specimens Marshall and bulk density tests were performed according to EN 12697-6 (procedure D) and air voids content according to EN 12697-8. Cantabro test was carried out according to EN 12697-17 and Spanish NLT 362 standard. This test allows to determine the four specimens maintained in air particle loss (PA) for $48 \mathrm{~h}$ at $25^{\circ} \mathrm{C}$, and of the four specimens maintained in water particle loss (PS) for $24 \mathrm{~h}$ at $60^{\circ} \mathrm{C}$ and then heated for a further $24 \mathrm{~h}$ at $25^{\circ} \mathrm{C}$. The test was carried out in Los Angeles equipment, with 300 rotations, without metal balls. The PS results for each bitumen percentage must meet the stablished requirements for the Cantabro test.

\subsubsection{Cellulosic fibres influence by the Schellenberg method}

The aim of the cellulosic fibres use is to obtain discontinuous and porous mixtures with relatively high binder content, with any observation of the binder drainage while being stored and/or transported. The cellulosic fibres addition does not allow dissimilarities appearance in the applied layer characteristics, such as very different air voids content and consequent premature degradation. The cellulosic fibres retain the binder and favour aggregates coating, leading to mixtures higher performance and durability. Given this situation, in mixtures with fibres addition, it was chosen the use of a higher bitumen percentage.

The cellulosic fibres influence was analysed by determination of the porous asphalt binder drainage by Schellenberg Method according to EN 12697-18 standard. The mixtures were made with different cellulosic fibres percentages ranging from 0.0, 0.2, 0.4 and $0.5 \%$ (recommended limit by the manufacturer). The procedure consisted of producing three mixtures specimens for each fibres percentage by heating them for $60 \mathrm{~min}$ at the test temperature, in this case $180^{\circ} \mathrm{C}$. Through the waste mixture weight ratio after the $60 \mathrm{~min}$ heating and the mixture weight immediately after being produced, the binder drainage percentage is obtained. The final result was the three specimens average made by percentage of fibres used.

\subsubsection{Mixtures with cellulosic fibres characterization}

After selecting the percentage of the most appropriate fibre to porous asphalt mixtures produced in the previous section were characterized both porous asphalt mixtures with fibres PA1 (porous asphalt with fine aggregates, with fibres) and PA2 (porous asphalt with coarse aggregates, with fibres). The properties determined to bulk density, air voids content and particle loss by Cantabro test, wet and dry.

\subsubsection{Stiffness}

The stiffness was obtained by Indirect Tensile Stiffness Modulus (ITSM) performed according to EN 12697-26 standard, using Nottingham Asphalt Tester (NAT) equipment. Six cylindrical specimens were made, with an impact compactor by applying 50 blows in each side, for each of the optimum bitumen percentage of the four porous asphalt mixtures, totalling 24 specimens, with about $100 \mathrm{~mm}$ diameter and different heights. The test was performed in tension controlled conditions through deformation evolution. The test conditions were: $20^{\circ} \mathrm{C}$ test temperature, 0.35 Poisson's ratio, $124 \mathrm{~ms}$ rise time and a $5 \mu \mathrm{m}$ target peak transient horizontal deformation.

The stiffness was obtained through the application of ten repeated loads to each test specimen, in diametric and orthogonal directions, and by measuring the respective recorded transient deformations by LVDT sensors (Linear Variable Displacement Transducer).

\subsubsection{Water sensitivity test}

The water sensitivity evaluation to porous asphalt is important, because this is a property that is directly related to the mixtures performance and durability during the pavement life time. The water sensitivity test was performed according to EN 12697-12 standard. Six cylindrical specimens were made for each optimum bitumen percentage by applying 50 blows in each side. These were 
separated into two groups. The dry specimens were maintained in air at $20^{\circ} \mathrm{C}$ for a period of 68 to $72 \mathrm{~h}$. The wet specimens were previously subjected to vacuum in water for during $30 \mathrm{~min}$ under an absolute pressure of $6.7 \mathrm{kPa}$ followed by water bath at $20^{\circ} \mathrm{C}$ of 68 to $72 \mathrm{~h}$. Then, the two groups were tested to indirect tensile strength, according to EN 12697-23 standard, with a load applied at a $50 \mathrm{~mm} / \mathrm{min}$ constant velocity. The water sensitivity test results are Indirect Tensile Strength Ratio (ITRS) by EN 12697-12 and Tensile Strength Indirect (ITS) by EN 12697-23.

\subsubsection{Permeability test}

Permeability is one of the most important characteristics in porous asphalt. This is the property that provides infiltration and storage by allowing the control of the stormwater runoff.

In this study, it was used a variable load device, similar to the LCS permeameter (Laboratorio de la Cátedra de Caminos de Santander) developed in Spain, to perform the permeability test, vertical and horizontal, into cylindrical test specimens compacted in the laboratory. The vertical permeability represents a unidirectional flow vertical and the horizontal permeability represents the flow conditions occurring during a rainfall. The EN 12697-19 has a different permeability measuring permeameter. However, the permeability coefficient for both permeameters is determined based on Darcy's law, according to the Eq. (1).

$k=\frac{a \times L}{A \times \Delta t} \times \ln \left(\frac{h_{1}}{h_{2}}\right)(\mathrm{m} / \mathrm{s})$

where $k$ is the permeability coefficient ( $\mathrm{m} / \mathrm{s}), a$ is cross section area of standpipe $\left(\mathrm{m}^{2}\right), A$ is cross section area of specimen $\left(\mathrm{m}^{2}\right), L$ is height of specimen $(\mathrm{m}), \Delta t$ is time interval taken for water in the standpipe to fall from $h_{1}$ to $h_{2}(\mathrm{~s}), h_{1}$ is the head at the beginning of time measurement (m) and $h_{2}$ is head at the end of time measurement $(\mathrm{m})$.

This law assumes that the specimen was saturated, it was homogeneous and the flow was laminar. Several authors question the Darcy's law applicability stating that the flow in porous asphalt is turbulent [50-52]. In this study it was used the permeameter based on Darcy's law due to its simplicity and to the lack of equipment that takes into account the turbulent flow in the specimens. In the variable load device used the permeability was measured by the time it takes to drain a $1735 \mathrm{~cm}^{3}$ water volume through porous asphalt. For each mixture optimum bitumen percentage were produced four cylindrical specimens.

\subsubsection{Resistance to permanent deformation}

The resistance to permanent deformation for four mixtures was assessed by the Wheel Tracking Test, according to the EN 12697-22 standard, using a small device and the B procedure (in air). Two slabs were prepared for each mixture with $30 \times 30 \times 4 \mathrm{~cm}$ dimensions, compacted with a vibratory compactor. The test began after 7 days of curing time. The test execution temperature was $60^{\circ} \mathrm{C}$ and the slabs were conditioned at the same temperature, before the test during a minimum time of $4 \mathrm{~h}$. The load applied was $700 \mathrm{~N}$ at a frequency of $26.5 \pm 1.0$ load cycles/min. The test ended after 10,000 cycles were applied. The parameters obtained for this test were the Wheel Tracking Slope in air $\left(\mathrm{WTS}_{\mathrm{AIR}}\right)$ and the mean Rut Depth in air $\left(\mathrm{RD}_{\mathrm{AIR}}\right)$.

\section{Results and discussion}

\subsection{Optimum bitumen percentage analysis for the mixtures without cellulosic fibres}

The composition of PA01 and PA02 mixtures study are shown in Table 3 and particle size distribution in Table 4. Both tables include porous asphalt mixtures with fibres (PA1 and PA2), since the par-
Table 3

Porous asphalt composition (\%).

\begin{tabular}{lllll}
\hline Materials & PA01 & PA1 & PA02 & PA2 \\
\hline PMB 45/80 bitumen & 4.7 & 4.7 & 4.6 & 4.6 \\
Hydraulic lime & 2 & 2 & 2 & 2 \\
Stone dust & 8 & 8 & 4 & 4 \\
5/15 Gravel & - & - & 94 & 94 \\
5/10 Gravel & 90 & 90 & - & - \\
\hline
\end{tabular}

* Weight percentage of total aggregates.

Table 4

Porous asphalt particle size distribution.

\begin{tabular}{llllll}
\hline $\begin{array}{l}\text { Sieve size } \\
(\mathrm{mm})\end{array}$ & \% Passing & $\begin{array}{l}\text { PA 8 Envelope } \\
(\text { SN 640) }\end{array}$ & $\begin{array}{l}\text { Sieve size } \\
(\mathrm{mm})\end{array}$ & \% Passing & $\begin{array}{l}\text { PA 12,5 } \\
\text { Envelope } \\
\text { (CE EP) }\end{array}$ \\
& PA01/PA1 & & & PA02/PA2 & \\
\hline 16 & 100 & 100 & 20 & 100 & $100-100$ \\
11.2 & 99 & 100 & 12.5 & 99 & $90-100$ \\
8 & 73 & $90-100$ & 10 & 79 & $55-75$ \\
4 & 25 & $15-35$ & 4 & 12 & $13-30$ \\
2 & 12 & $10-17$ & 2 & 8 & $11-18$ \\
0.5 & 5 & $4-10$ & 1 & 6 & $6-14$ \\
0.063 & 2 & $3-5$ & 0.063 & 2 & $2-5$ \\
\hline
\end{tabular}

ticle size depends only of aggregates and does not depend on the additive percentage. From the analysis of Table 4 it was verified a failure in the sieve size of $8 \mathrm{~mm}$ for porous asphalt with fine aggregates and 10 and $2 \mathrm{~mm}$ sieve size for porous asphalt with coarse aggregates. This was due to the aggregates grading curve which comprises the mixtures, which could not fit in the grading envelope ensuring the most important air voids content requirement. Thus, it was decided to ensure the mixtures air voids content despite of the grading envelope occasional failure.

The results of bulk density, air voids content, dry and wet Cantabro test are represented in Table 5 . Both porous asphalt mixtures meet the minimum bitumen percentage and air voids requirement of 16\% according to the FHWA and UNHSC, as well as the result of the wet Cantabro test. For PA01 mixture was adopted an optimum percentage of $4.7 \%$, because it presented the best visual aspect and total aggregates coating. For PA02 mixture was considered the optimum bitumen percentage of $4.6 \%$ since it presents the lower result value of wet Cantabro test.

\subsection{Cellulosic fibres influence by the Schellenberg method}

The mixtures production with cellulosic fibres addition was carried out with the highest percentages of bitumen obtained in the mix design of the mixtures without fibres. This choice was due to the binder retention capacity on the fibres part, preventing the mixtures dry aspect. Thus, the $5.2 \%$ and $5.1 \%$ bitumen percentages were used for porous asphalt containing more fine aggregates

Table 5

Porous asphalt without fibres mechanical and volumetric properties ( 8 specimens average).

\begin{tabular}{llllll}
\hline $\begin{array}{l}\text { Porous } \\
\text { Asphalt }\end{array}$ & $\begin{array}{l}\text { \% PMB } \\
45 / 80 \\
\text { Bitumen }\end{array}$ & $\begin{array}{l}\text { Bulk } \\
\text { density } \\
\left(\mathrm{kg} / \mathrm{m}^{3}\right)\end{array}$ & $\begin{array}{l}\text { Air voids } \\
\text { content } \\
(\%)\end{array}$ & $\begin{array}{l}\text { Dry } \\
\text { Cantabro } \\
\text { test (PS) }(\%)\end{array}$ & $\begin{array}{l}\text { Wet } \\
\text { Cantabro test } \\
(\text { PS) (\%) }\end{array}$ \\
\hline PA01 & 4.2 & 1930 & 20.5 & 15 & 14 \\
& 4.7 & 1940 & 19.6 & 12 & 15 \\
& 5.2 & 1940 & 19.0 & 9 & 16 \\
PA02 & 4.1 & 1930 & 21.9 & 11 & 13 \\
& 4.6 & 1950 & 20.7 & 7 & 8 \\
& 5.1 & 1890 & 22.2 & 8 & 15 \\
\hline
\end{tabular}




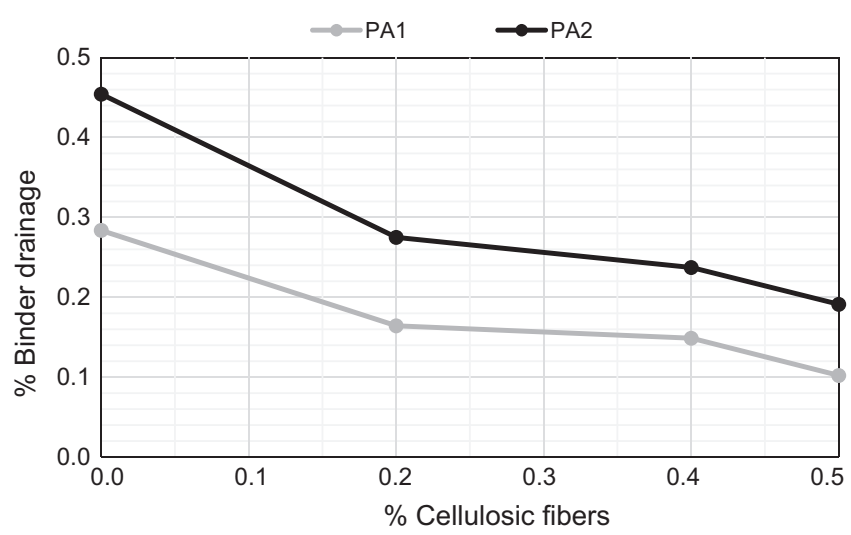

Fig. 2. Porous asphalt binder drainage results (3 specimens average).

(PA1) and coarse aggregates (PA2), respectively, varying the amount of fibres at 0.0, 0.2, 0.4 and $0.5 \%$ (recommended limit by the manufacturer). The obtained results by Schellenberg method are shown in Fig. 2. It was observed that overall, the binder drainage decreases as the percentage of cellulosic fibres increases. It was found that the PA2 mixture obtained more binder drainage than the PA1 mixture, independently of the used fibres percentage. This may be due to the aggregates use with a bigger nominal size (smaller specific surface area) as well as the use of a more discontinuous grading curve. The use of $0.5 \%$ cellulosic fibres for PA1 and

Table 6

Porous asphalt with fibres mechanical and volumetric properties (8 specimens average).

\begin{tabular}{lll}
\hline Porous Asphalt & PA1 & PA2 \\
\hline \% PMB 45/80 Bitumen & 5.2 & 5.1 \\
Bulk density $\left(\mathrm{kg} / \mathrm{m}^{3}\right)$ & 1960 & 1940 \\
Air voids content (\%) & 16.6 & 18.6 \\
Dry Cantabro test (PA) (\%) & 7 & 9 \\
Wet Cantabro test (PS) (\%) & 28 & 21
\end{tabular}

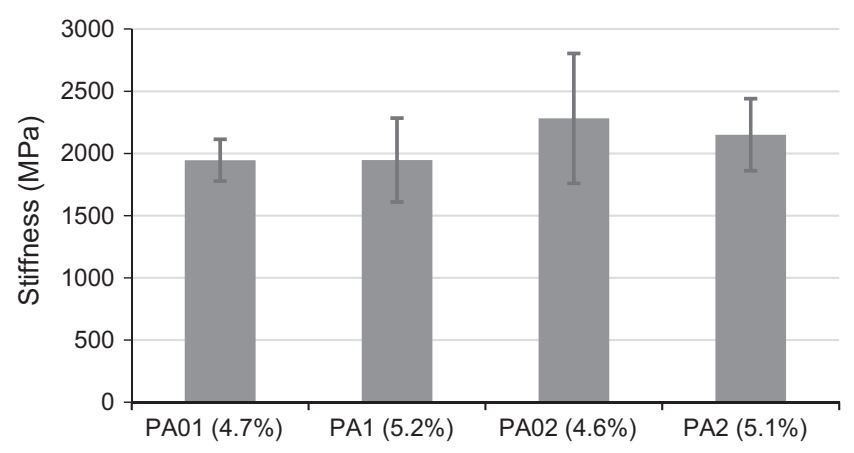

Fig. 3. Stiffness results (6 specimens average).

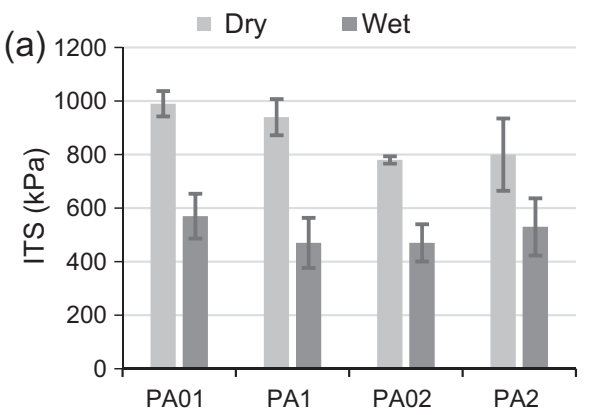

PA2 mixtures showed a reduction of 0.2 and $0.3 \%$, respectively, comparing to mixtures with $0.0 \%$ fibres. Taking into account the results, the selected percentage of cellulosic fibres as the most suitable for both porous asphalt was of $0.5 \%$. The performance tests presented bellow characterize these mixtures and the mixtures without cellulosic fibres.

\subsection{Mixtures with cellulosic fibres characterization}

The properties shown in Table 6 were studied for porous asphalt with $0.5 \%$ cellulosic fibres, value considered the most appropriate in the previous section. The two porous asphalt mixtures with fibres comply with the requirement of $16 \%$ air voids content according to the UNHSC and FHWA. Regarding the Cantabro test results, specimens in water (PS) showed more significant losses than the dry test specimens (PA), however, remains within or near the given limits. These particle losses can be explained by the water temperature of $60^{\circ} \mathrm{C}$ which influences the disaggregation resistance.

\subsection{Stiffness results}

The results presented in Fig. 3 indicate the average of the six test specimens by mixture. The stiffness modulus for the two mixtures groups (with and without cellulosic fibres) presented very similar values between them. Note that the PA1 and PA01 mixtures showed a stiffness slight decrease of about $12.2 \%$ compared to PA02 and PA2 mixtures, due to its structure with more mastic, absorbing better the induced stresses.

\subsection{Water sensibility results}

Fig. 4 shows the results of the water sensitivity test. The dry specimens show higher ITS values as expected due to the presence of water at $40^{\circ} \mathrm{C}$ in the wet specimens, showing more for the porous asphalt containing more fine aggregates. Small differences are found in the four mixtures ITSR values, around $8 \%$. It was observed that porous asphalt containing more fine aggregates, PA1 and PA01 are more susceptible to the water presence than mixtures with coarse aggregates. The PA02 and PA2 mixtures have more air voids which allow water to pass easily leading to ITSR higher values. The SN 640 standard indicates a value for porous asphalt above $70 \%$. Porous asphalt studied did not accomplish this limit, but the results are very close to this value.

\subsection{Permeability results}

Analysing the results of Figs. 5 and 6 it can be seen that the flow time is inversely proportional to the permeability coefficient. The PA02 mixture had a lower flow time than the PA01 mixture, because their internal structure had more air voids content and it allowed water to pass through more quickly. The PA1 and PA2 mix-

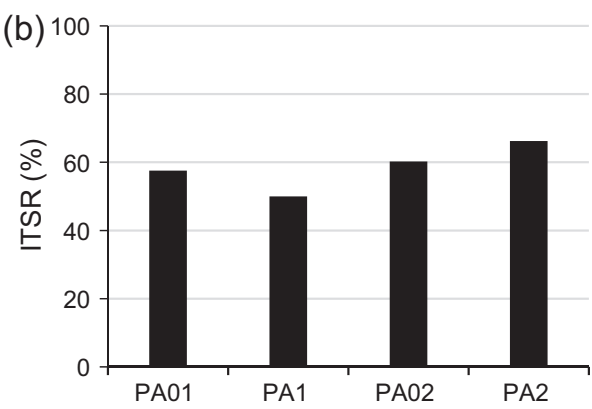

Fig. 4. (a) Indirect Tensile Strength results ( 3 specimens average) (b) Indirect Tensile Strength Ratio results. 


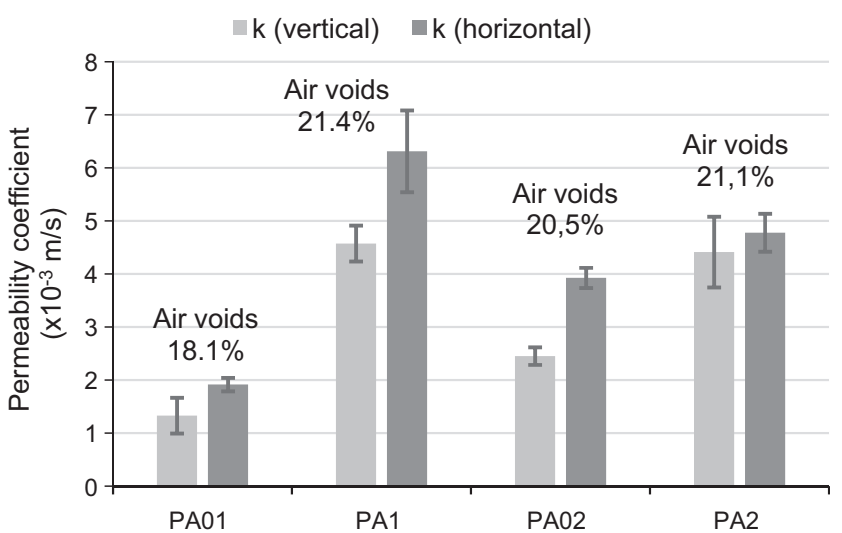

Fig. 5. Permeability coefficient results (4 specimens average).

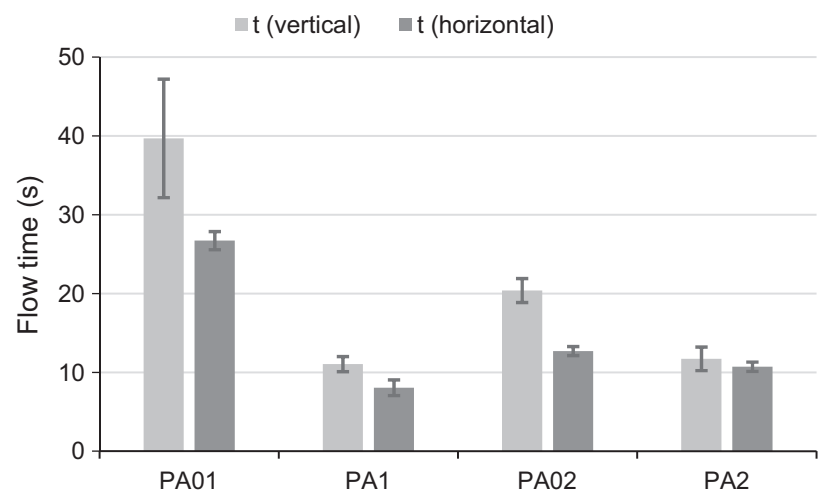

Fig. 6. Flow time in the permeability test ( 4 specimens average).

tures did not follow this trend and it was verified a slight increase in the flow time for the PA2 mixture, noting that this mixture was less permeable than the PA1 mixture, a situation which can be due to a deficiency in the specimens sealing with the permeameter, since they have very similar air voids content. Comparing the mixtures with and without cellulosic fibres addition was observed that PA01 and PA02 had lower permeability, in vertical of $19 \mathrm{~s}$ and horizontal of $10 \mathrm{~s}$, than PA1 and PA2. In this case, it was evident that the fibres presence in the mixtures allowed the binder absorption, preventing that it remains dispersed, occupying the air voids content. The PA1 mixture provides the best results for the water flow, being the PA01 mixture the one that shows the lowest values, result of the high flow time. This was due to the big number of fine aggregates in the mixture interfering with their permeability.

\subsection{Resistance to permanent deformation}

Fig. 7 shows the obtained results for number of cycles rut depth for both porous asphalt mixtures with and without cellulosic fibres addition. In this figure, it is possible to observe the effect of the cellulosic fibres addition on the different mixtures permanent deformation performance. Both PA1 mixture and PA2 have shown an improved performance in terms of rut resistance, as it can be observed by the curves with lower rut depth. These good results are related to the improvement of the bitumen/aggregate adhesion, provided by the additive. In this case, it can be concluded that cellulosic fibres do not increase the porous asphalt susceptibility to the permanent deformation.

Table 7 shows the results obtained in the Wheel Tracking tests, according to the main parameters that characterize their resistance to permanent deformation. Note that the slabs air voids content was higher than those obtained in the Cantabro test, referring to

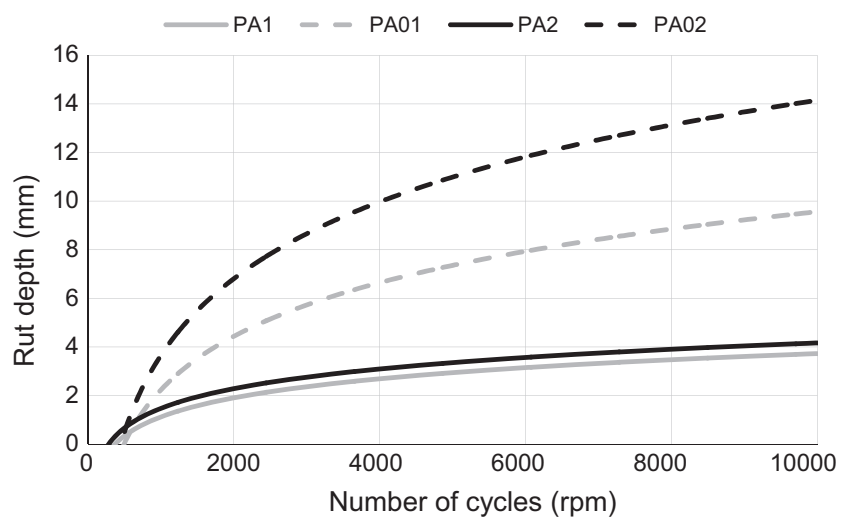

Fig. 7. Wheel Tracking test results obtained for the studied mixtures, at $60{ }^{\circ} \mathrm{C}(2$ slabs average).

Table 7

Main parameters obtained in the Wheel Tracking tests (2 slabs average).

\begin{tabular}{|c|c|c|c|c|}
\hline \multirow[t]{2}{*}{ Parameters } & \multicolumn{2}{|c|}{$\begin{array}{l}\text { Mixtures without } \\
\text { fibres }\end{array}$} & \multicolumn{2}{|c|}{$\begin{array}{l}\text { Mixtures with } \\
\text { fibres }\end{array}$} \\
\hline & PA01 & PA02 & PA1 & PA2 \\
\hline Air voids content (\%) & 24.0 & 27.3 & 22.6 & 26.5 \\
\hline $\begin{array}{l}\text { Wheel Tracking slope } \\
\qquad\left(\mathrm{WTS}_{\mathrm{AIR}}\right)\left(\mathrm{mm} / 10^{3} \text { cycles }\right)\end{array}$ & 0.84 & 0.09 & 0.49 & 0.45 \\
\hline Rut depth $\left(\mathrm{RD}_{\mathrm{AIR}}\right)(\mathrm{mm})$ & 10.90 & 13.97 & 4.94 & 5.21 \\
\hline
\end{tabular}

the difference in the compaction method. It is observed in Table 7 , that the cellulosic fibres effect is slightly larger in PA1 than in PA2 due to its structure with less air voids and by the $\mathrm{WTS}_{\text {AIR }}$ value reduction. In PA01 mixture is possible to see better that composition influence. In porous asphalt without fibres it was found that the bitumen worked as a lubricating in the aggregates links, increasing the $\mathrm{RD}_{\mathrm{AIR}}$. The PA02 mixture showed the highest $\mathrm{RD}_{\mathrm{AIR}}$

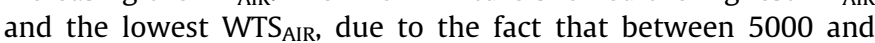
10,000 cycles, the deformation is almost constant, varying only $0.47 \mathrm{~mm}$. This demonstration can't be observed in the figure due to the lines of logarithmic trend representation, which facilitated the curves tracing.

In this study, it was clear the improvement of the resistance to porous asphalt with fibres permanent deformation, with bitumen higher percentages than the conventional porous asphalt. This bitumen increase leads to a bigger mixtures durability.

\section{Conclusions}

This paper presents the performance of porous asphalt with and without cellulosic fibres addition. Through performed mix design higher bitumen percentages were obtained for porous asphalt with cellulosic fibres. The cellulosic fibres allowed to increase the bitumen percentage, enabling its retention and a better aggregates coating and, consequently, a bigger mixture durability. The tests done from this mix design allowed to obtain the following conclusions:

(1) In wet Cantabro test at $60^{\circ} \mathrm{C}$ it was found that the porous asphalt with added cellulosic fibres showed bigger particle loss values $(11 \%)$ than the porous asphalt without this addition, satisfying, however, the established requirements. It was noted that the water temperature in this test was a significant factor in porous asphalt with cellulosic fibres behaviour. 
(2) The addition of cellulosic fibres does not induce any significant change in the stiffness modulus obtained in an ITSM test because the results were quite similar.

(3) The water sensitivity results identify the porous asphalt with more fine aggregates with lower ITSR values (9\% in average) than the porous asphalt with coarse aggregates, being these last ones more resistant in water presence. All mixtures, with or without cellulosic fibres, presented similar results very close to those required for porous asphalt.

(4) Permeability is one of the most important properties in porous asphalt such as air voids content. It was concluded by the permeability test that the mixtures with fine and coarse aggregates with added fibres present bigger coefficients of vertical and horizontal permeability, in $0.5 \times 10^{-3}$ and $1 \times 10^{-3} \mathrm{~m} / \mathrm{s}$, respectively. These results showed that the use of fibres in the mixtures composition improves its performance for runoff in a pavement, when compared to the mixtures without this addition. Thus, the incorporation of cellulosic fibres to absorb more binder allows the water drainage between the mixture voids.

(5) In general, resistance to permanent deformation results indicated better behaviour of porous asphalt with cellulosic fibres, verifying a bigger rut depth to porous asphalt without cellulosic fibres, of $7 \mathrm{~mm}$. In this study, it was observed that porous asphalt with bitumen higher percentages improve the performance to permanent deformation. This fact was only possible due to the bitumen retention by the cellulosic fibres.

In conclusion, the cellulosic fibres addition in porous asphalt leads to good results in mechanical performance, allowing the use of such mixtures with durability guarantees, good functioning and, consequently, users safety, especially in what concerns aquaplaning phenomena.

\section{Acknowledgments}

The authors would like to acknowledge JRS, J. Rettenmaier \& Söhne, for the cellulosic fibres supply, CEPSA for the modified bitumen supply and Pedreira da Capinha for the new aggregates supply.

\section{References}

[1] United Nations, World Population Prospects: The 2015 Revision, Dep. Econ. Soc. Aff. Popul. Div, 2015.

[2] E. Gomez-Ullate, E. Castillo-Lopez, D. Castro-Fresno, J.R. Bayon, Analysis and contrast of different pervious pavements for management of storm-water in a parking area in Northern Spain, Water Resour. Manage. 25 (2011) 1525-1535, http://dx.doi.org/10.1007/s11269-010-9758-x.

[3] H.T.L. Huong, A. Pathirana, Urbanization and climate change impacts on future urban flooding in Can Tho city, Vietnam, Hydrol. Earth Syst. Sci. 17 (2013) 379394, http://dx.doi.org/10.5194/hess-17-379-2013.

[4] A.H. Elliott, S.A. Trowsdale, A review of models for low impact urban stormwater drainage, Environ. Model. Software 22 (2007) 394-405, http:// dx.doi.org/10.1016/j.envsoft.2005.12.005.

[5] R. Ghazal, A. Ardeshir, I. Zahedi Rad, Climate change and stormwater management strategies in Tehran, Procedia Eng. 89 (2014) 780-787, http:// dx.doi.org/10.1016/j.proeng.2014.11.507.

[6] J. Huang, J. He, C. Valeo, A. Chu, Temporal evolution modeling of hydraulic and water quality performance of permeable pavements, J. Hydrol. 533 (2016) 1527, http://dx.doi.org/10.1016/j.jhydrol.2015.11.042.

[7] L. Leopold, Hydrology for urban land planning - a guidebook on the hydrologic effects of urban land use, Geol. Surv. Circ. 554 (1968).

[8] P. Willems, K. Arnbjerg-Nielsen, J. Olsson, V.T.V. Nguyen, Climate change impact assessment on urban rainfall extremes and urban drainage: methods and shortcomings, Atmos. Res. 103 (2012) 106-118, http://dx.doi.org/10.1016/ j.atmosres.2011.04.003.

[9] Q. Zhou, A Review of sustainable urban drainage systems considering the climate change and urbanization impacts, Water 6 (2014) 976-992, http://dx. doi.org/10.3390/w6040976.
[10] J.E. Ball, K. Rankin, The hydrological performance of a permeable pavement, Urban Water J. 7 (2010) 79-90, http://dx.doi.org/10.1080/ 15730620902969773 .

[11] H.M. Imran, S. Akib, M.R. Karim, Permeable pavement and stormwater management systems: a review, Environ. Technol. 34 (2013) 2649-2656, http://dx.doi.org/10.1080/09593330.2013.782573.

[12] R.M. Roseen, T.P. Ballestero, K. Houle, D. Heath, J.J. Houle, Assessment of winter maintenance of porous asphalt and its function for chloride source control, J. Trans. Eng. 140 (2014) 1-8, http://dx.doi.org/10.1061/(ASCE)TE.19435436.0000618.

[13] C.F. Carvalho, Study of permeable pavements in urban areas Evaluation of his efficiency in order to reduce the runoff, in: Int. Conf. Eng. ICEUBI2015 - Eng. Soc., University of Beira Interior, Covilhã, Portugal, 2015, p. 9. Paper 135.

[14] R. Elvik, P. Greibe, Road safety effects of porous asphalt: a systematic review of evaluation studies, Accid. Anal. Prev. 37 (2005) 515-522, http://dx.doi.org/ 10.1016/j.aap.2005.01.003.

[15] W. Jiang, A. Sha, J. Xiao, Y. Li, Y. Huang, Experimental study on filtration effect and mechanism of pavement runoff in permeable asphalt pavement, Constr. Build. Mater. 100 (2015) 102-110, http://dx.doi.org/10.1016/ j.conbuildmat.2015.09.055.

[16] C.J. Pratt, J.D.G. Mantle, P.A. Schofield, UK research into the performance of permeable pavement, reservoir structures in controlling stormwater discharge quantity and quality, Water Sci. Technol. 32 (1995) 63-69, http://dx.doi.org/ 10.1016/0273-1223(95)00539-Y.

[17] V. Hirsch, O. Ripke, Lessons learned from streets - porous asphalt, News Info Viatop ${ }^{\circledR}$ Fiber Pellets, J. Rettenmaier Söhne - JRS (2008).

[18] M. Liu, X. Huang, G. Xue, Effects of double layer porous asphalt pavement of urban streets on noise reduction, Int. J. Sustainable Built Environ. 5 (2016) 183-196, http://dx.doi.org/10.1016/j.ijsbe.2016.02.001.

[19] A.M. Al-Rubaei, A.L. Stenglein, M. Viklander, G.-T. Blecken, Long-term hydraulic performance of porous asphalt pavements in Northern Sweden, J. Irrig. Drain. Eng. 139 (2013) 499-505, http://dx.doi.org/10.1061/(ASCE) IR.1943-4774.0000569.

[20] B.O. Brattebo, D.B. Booth, Long-term stormwater quantity and quality performance of permeable pavement systems, Water Res. 37 (2003) 43694376, http://dx.doi.org/10.1016/S0043-1354(03)00410-X.

[21] Federal Highway Administration, TechBrief: Porous asphalt pavements with stone reservoirs, FHWA-HIF-15-009. (2015) $11 . \quad<$ http://www. fhwa.dot.gov/pavement/asphalt/pubs/hif15009.pdf>.

[22] M.A. Hernandez-Saenz, S. Caro, E. Arámbula-Mercado, A. Epps, Martin, mix design, performance and maintenance of permeable friction courses (PFC) in the United States: state of the art, Constr. Build. Mater. 111 (2016) 358-367, http://dx.doi.org/10.1016/j.conbuildmat.2016.02.053.

[23] K. Kumar, J. Kozak, L. Hundal, A. Cox, H. Zhang, T. Granato, In-situ infiltration performance of different permeable pavements in a employee used parking lot - a four-year study, J. Environ. Manage. 167 (2016) 8-14, http://dx.doi.org 10.1016/j.jenvman.2015.11.019.

[24] Y. Zhang, M. van de Ven, A. Molenaar, S. Wu, Preventive maintenance of porous asphalt concrete using surface treatment technology, Mater. Des. 99 (2016) 262-272, http://dx.doi.org/10.1016/j.matdes.2016.03.082.

[25] CEPSA, Manual de pavimentação, 3a Edição., CEPSA Betumes, Lisboa, Portugal, 2014.

[26] R.B. Mallick, P.S. Kandhal, L.A. Cooley, D.E. Watson, Design, construction, and performance of new-generation open-graded friction courses, 2000.

[27] L.D. Poulikakos, M.N. Partl, Investigation of porous asphalt microstructure using optical and electron microscopy, J. Microsc. 240 (2010) 145-154, http:// dx.doi.org/10.1111/j.1365-2818.2010.03388.x.

[28] A. Chowdhury, J.W. Button, A. Bhasin, Fibers from recycled tire as reinforcement in Hot Mix Asphalt, Texas Transp. Inst. (2006) 58. <http:// swutc.tamu.edu/Reports/167453-1.pdf>.

[29] H. Fazaeli, Y. Samin, A. Pirnoun, A.S. Dabiri, Laboratory and field evaluation of the warm fiber reinforced high performance asphalt mixtures (case study Karaj - Chaloos Road), Constr. Build. Mater. 122 (2016) 273-283, http://dx.doi. org/10.1016/j.conbuildmat.2016.05.139.

[30] Z. Fu, Y. Dang, B. Guo, Y. Huang, Laboratory investigation on the properties of asphalt mixtures modified with double-adding admixtures and sensitivity analysis, J. Traffic Transp. Eng. (2016) 412-426, http://dx.doi.org/10.1016/j. jtte.2016.09.002 (English Ed. 3).

[31] K.E. Kaloush, K.P. Biligiri, W.A. Zeiada, M.C. Rodezno, J.X. Reed, Evaluation of fiber-reinforced asphalt mixtures using advanced material characterization tests, J. Test. Eval. 38 (2010) 1-12, http://dx.doi.org/10.1520/JTE102442.

[32] A. Mahrez, M.R. Karim, Rutting characteristics of bituminous mixes reinforced with glass fiber, J. East Asia Soc. Transp. Stud. 7 (2007) 2168-2178, http://dx. doi.org/10.11175/easts.7.2168.

[33] M. Manosalvas-Paredes, J. Gallego, L. Saiz, J.M. Bermejo, Rubber modified binders as an alternative to cellulose fiber - SBS polymers in stone matrix asphalt, Constr. Build. Mater. 121 (2016) 727-732, http://dx.doi.org/10.1016/ j.conbuildmat.2016.06.028.

[34] R. McDaniel, Fiber additives in asphalt mixtures, National Cooperative Highway Research Program, 2015.

[35] B.J. Putman, S.N. Amirkhanian, Utilization of waste fibers in stone matrix asphalt mixtures, Resour. Conserv. Recycl. 42 (2004) 265-274, http://dx.doi. org/10.1016/j.resconrec.2004.04.005.

[36] W. Shao-peng, L. Gang, M. Lian-tong, C. Zheng, Y. Qun-shan, Effect of fiber types on relevant properties of porous asphalt, Trans. Nonferrous Met. Soc. China 16 (2006) 791-795, http://dx.doi.org/10.1016/S1003-6326(06)60302-6. 
[37] M. Ardanuy, J. Claramunt, R.D. Toledo Filho, Cellulosic fiber reinforced cementbased composites: a review of recent research, Constr. Build. Mater. 79 (2015) 115-128, http://dx.doi.org/10.1016/j.conbuildmat.2015.01.035.

[38] G. Ferrotti, E. Pasquini, F. Canestrari, Experimental characterization of highperformance fiber-reinforced cold mix asphalt mixtures, Constr. Build. Mater. 57 (2014) 117-125, http://dx.doi.org/10.1016/j.conbuildmat.2014.01.089.

[39] P.S. Kandhal, Design, construction and maintenance of open-graded asphalt friction courses, Natl. Aphalt Pavement Assoc. 115 (2002) 29.

[40] K.R. Lyons, B.J. Putman, Laboratory evaluation of stabilizing methods for porous asphalt mixtures, Constr. Build. Mater. 49 (2013) 772-780, http://dx. doi.org/10.1016/j.conbuildmat.2013.08.076.

[41] B.J. Putman, Evaluation of open-graded friction courses: construction, maintenance, and performance, South Carolina Dep. Transp. Coop. with FHWA Rep. No. FHWA-SC-12-04. (2012) 119.

[42] L. Yan, B. Kasal, L. Huang, A review of recent research on the use of cellulosic fibres, their fibre fabric reinforced cementitious, geo-polymer and polymer composites in civil engineering, Compos. Part B Eng. 92 (2016) 94-132, http:// dx.doi.org/10.1016/j.compositesb.2016.02.002.

[43] K.G. Satyanarayana, G.G.C. Arizaga, F. Wypych, Biodegradable composites based on lignocellulosic fibers-an overview, Prog. Polym. Sci. 34 (2009) 9821021, http://dx.doi.org/10.1016/j.progpolymsci.2008.12.002.

[44] P. Wambua, J. Ivens, I. Verpoest, Natural fibres: can they replace glass in fibre reinforced plastics?, Compos Sci. Technol. 63 (2003) 1259-1264, http://dx.doi. org/10.1016/S0266-3538(03)00096-4.
[45] F. Martinho, S. Lanchas, R. Nunez, F. Batista, H. Miranda, A experiência portuguesa em misturas betuminosas do tipo SMA com fibras celulósicas, 7 Congr. Rodoviário Port. Lisboa. (2013) 1-10.

[46] C. Sangiorgi, P. Tataranni, A. Simone, V. Vignali, C. Lantieri, G. Dondi, Assessment of waste bleaching clay as alternative filler for the production of porous asphalts, Constr. Build. Mater. 109 (2016) 1-7, http://dx.doi.org/ 10.1016/j.conbuildmat.2016.01.052.

[47] S.A. Estradas de Portugal, Caderno de Encargos Tipo Obra, 14.03 Pavimentação Características dos materiais, 2014. <http://www. infraestruturasdeportugal.pt/sites/default/files/cet/14_03_set_2014.pdf>.

[48] PROAS, Vademécum pavimentos asfálticos, PROAS (Produtos Asfálticos, S.A.), 11a Edição, Espanã, 2013.

[49] University of New Hampshire Stormwater Center, UNHSC Design Specifications for Porous Asphalt Pavement and Infiltration Beds, Univ. New Hampsh. Stormwater Cent. (2014) 28.

[50] T.F. Fwa, S.A. Tan, C.T. Chuai, Y.K. Guwe, Expedient permeability measurement for porous pavement surface, Int. J. Pavement Eng. 2 (2001) 259-270, http:// dx.doi.org/10.1080/10298430108901731.

[51] M.O. Hamzah, M.R.M. Hasan, M. van de Ven, Permeability loss in porous asphalt due to binder creep, Constr. Build. Mater. 30 (2012) 10-15, http://dx. doi.org/10.1016/j.conbuildmat.2011.11.038.

[52] H. Xu, W. Guo, Y. Tan, Permeability of asphalt mixtures exposed to freeze-thaw cycles, Cold Reg. Sci. Technol. 123 (2016) 99-106, http://dx.doi.org/10.1016/ j.coldregions.2015.12.001. 